Article

\title{
Antibacterial Activity of Four Human Beta-Defensins: HBD-19, HBD-23, HBD-27, and HBD-29
}

\author{
Bryan T. Chow ${ }^{\dagger}$, Maira Soto ${ }^{\dagger}$, Bonnie L. Lo, David C. Crosby and David Camerini * \\ Department of Molecular Biology and Biochemistry, School of Biological Sciences, University of \\ California, Irvine, CA 92697, USA; E-Mails: btchowuci@gmail.com (B.T.C.); \\ ariam2010@yahoo.com (M.S.); bonnielaurentlo@gmail.com (B.L.L.); \\ david.crosby@ucsf.edu (D.C.C.) \\ * Author to whom correspondence should be addressed; E-Mail: david.camerini@uci.edu; \\ Tel.: 01-949-824-1502; Fax: 01-949-824-2305. \\ $\dagger$ These authors contributed equally to this work.
}

Received: 1 February 2012; in revised form: 21 February 2012 / Accepted: 21 February 2012 / Published: 1 March 2012

\begin{abstract}
Human $\beta$-defensins (HBD) are a family of small antimicrobial peptides that play important roles in the innate and adaptive immune defenses against microbial infection. In this study, we predicted the mature sequences and assessed the antibacterial properties of synthetic HBD-19, HBD-23, HBD-27, and HBD-29 against three species of clinically relevant bacteria: Escherichia coli, Staphylococcus aureus and Pseudomonas aeruginosa. We also examined the cytotoxicity of each $\beta$-defensin to human cells. HBD-19 exhibited modest antibacterial effects against $E$. coli and $S$. aureus but had little effect on the growth of $P$. aeruginosa. HBD-23 exhibited substantial antibacterial effects against all three bacterial species and was particularly potent against the Gram-negative species, E. coli and $P$. aeruginosa. HBD-27 exerted modest antibacterial activity only towards $S$. aureus while HBD-29 had modest antibacterial activity for E. coli and P. aeruginosa. HBD-23 and HBD-27 showed little or no toxicity to human peripheral blood mononuclear cells, while HBD-19 and HBD-29 decreased cell viability by $20 \%$ at $30 \mu \mathrm{g} / \mathrm{mL}$.
\end{abstract}

Keywords: $\beta$-defensin; antibacterial; Escherichia coli; Staphylococcus aureus; Pseudomonas aeruginosa 


\section{Introduction}

Human $\beta$-defensins (HBD) are a family of cationic peptides that share a pattern of six cysteine residues forming three invariant disulfide bonds. Defensins constitute one of the first lines of innate immune defense against an array of bacteria, fungi, and viruses [1-5]. Many studies have demonstrated that human $\beta$-defensins, such as HBD-1, HBD-2, HBD-3, and HBD-4 are antimicrobial peptides expressed by epithelial cells initially as longer precursors [6-10]. Following processing to their mature forms, one of their mechanisms of action against bacteria is characterized by the electrostatic binding of cationic defensins with the negatively charged membrane $[11,12]$. This results in the disruption or perforation of the bacterial membrane, leading to cytoplasmic leakage and cell death $[13,14]$. Due to their broad microorganism-killing spectrum, $\beta$-defensins may be ideal candidates for the development of human antibiotics. Beta-defensins are also chemotactic for immature dendritic cells, memory helper T cells, monocytes, macrophages and activated neutrophils [6,15-18]. They provide a link between the innate and adaptive responses to microbial infection. The study of $\beta$-defensins will therefore lead to a greater understanding of innate and adaptive immunity at epithelial surfaces.

In this study, we report the antibacterial activities of four synthetic defensins whose mature sequences we predicted: HBD-19, HBD-23, HBD-27, and HBD-29. These peptides were chosen based on their common origin in the epithelial cell layer of the testis and epididymis [19-21]. Although these peptides differ in primary structure from known $\beta$-defensin peptides, they share a conserved arrangement of six cysteine residues with previously studied $\beta$-defensins and may therefore play important roles in defense against invading microbes in the male reproductive tract. The aims of this study were to characterize the antibacterial spectrum of these four human $\beta$-defensins, explore the effects of salt and a reducing agent on their antibacterial activities, and assess their cellular toxicity on human peripheral blood mononuclear cells (PBMC).

\section{Experimental Section}

\subsection{Predicting Mature Defensin Amino and Carboxy Termini}

SignalP, a computational tool available on the world-wide web [22] was used to predict the amino terminal signal peptide cleavage sites of HBD-19, HBD-23, HBD-27 and HBD-29. SignalP predictions were compared with known mature $\beta$-defensin peptide sequences to predict which amino terminal variants were most likely to yield biologically active $\beta$-defensins. Similarly, the mature carboxy termini of HBD-19, HBD-23, HBD-27 and HBD-29 were predicted by comparison with the known mature $\beta$-defensin peptide sequences.

\subsection{Reduction and Refolding of Synthetic Defensins}

HBD-23, HBD-27, and HBD-29 were chemically synthesized by Biosynthesis Inc. (Louisville, TX, USA) and HBD-19 was synthesized and kindly provided by Drs. Saskia Milton and Charles Glabe (University of California, Irvine). After reducing $4 \mathrm{mg}$ of synthetic defensins with $1 \mu \mathrm{g} / \mathrm{mL}$ dithiothreitol (DTT) at $55{ }^{\circ} \mathrm{C}$ for $4 \mathrm{~h}$, the peptides were passed through Sep-Pak cartridges with a C-8 sorbent, washed, and eluted with acetonitrile plus $0.1 \%$ trifluoroacetic acid. Peptides were dried overnight and 
subsequently dissolved in $0.1 \mathrm{M}$ ammonium carbonate buffer supplemented with $1 \mathrm{mM}$ cysteine and $1 \mathrm{mM}$ cystine under nitrogen gas [23]. The mixtures were stirred slowly at $25{ }^{\circ} \mathrm{C}$, allowing the peptides to refold. Peptides were examined every $24 \mathrm{~h}$ by $\mathrm{C}-18$ reverse-phase HPLC to assay the presence of foldamers. Peptides were further examined by reducing and non-reducing SDS-PAGE to assay the presence of multimers. Each lane was loaded with $3 \mu \mathrm{g}$ of peptide. Gels were stained with Coomassie blue dye and destained in (5\% (v/v) methanol, $7 \%(\mathrm{v} / \mathrm{v})$ acetic acid, $88 \% \mathrm{H}_{2} \mathrm{O}$. After seven days peptides were found to be $>95 \%$ monomeric, single foldamers.

\subsection{Antibacterial Activity Assays}

The colony forming unit (CFU) reduction assay was performed using Escherichia coli ML35 (provided by Dr. Andre Ouellette, University of Southern California), Staphylococcus aureus ATCC 25923, and Pseudomonas aeruginosa ATCC 27853 as described by Dr. Ouellette and colleagues [23]. Briefly, various concentrations of defensins were mixed with $1 \times 10^{6}$ to $5 \times 10^{6}$ bacteria in the logarithmic growth phase in $200 \mu \mathrm{L}$ of $10 \mathrm{mM}$ PIPES [piperazine-N,N'-bis (2-ethanesulfonic acid), $\mathrm{pH}$ 7.4] buffer and $1 \%$ (vol/vol) trypticase soy broth. These samples were incubated at $37{ }^{\circ} \mathrm{C}$ for $4 \mathrm{~h}$. After this incubation, samples were diluted 100-fold with cold $10 \mathrm{mM}$ PIPES and plated in triplicate on Luria broth agar. The plates were then incubated for 12 to $16 \mathrm{~h}$ at $37{ }^{\circ} \mathrm{C}$ and the number of colonies was recorded. In order to assess the effect of salt and a reducing agent on defensin activity, the PIPES buffer was supplemented with either $150 \mathrm{mM} \mathrm{NaCl}$ or $2 \mathrm{mM}$ dithiothreitol (DTT). As a positive bactericidal control, $20 \mathrm{mM}$ lysozyme was utilized. Statistical tests were performed with Student's two-tailed t-test.

\subsection{Cellular Toxicity Assay}

Human peripheral blood mononuclear cells (PBMCs) were purified from normal donor blood by centrifugation over Histopaque 1077 (Sigma) and $10^{5}$ cells were cultured in $100 \mu \mathrm{L}$ of media per well in 96-well plates. RPMI-1640 medium supplemented with $10 \%$ fetal bovine serum, $50 \mu \mathrm{g} / \mathrm{mL}$ gentamicin and 20 units/mL IL-2 was used. PBMC were incubated for three days with various concentrations of refolded or crude defensins. Thereafter, an MTS based metabolic assay (Promega) was utilized to examine the cytotoxicity of the defensins. The assay was conducted according to the manufacturer's specifications.

\section{Results}

\subsection{Predicting Mature Defensin Amino and Carboxy Termini}

The SignalP software tool was used to predict the amino terminal signal peptide cleavage sites of HBD-19, HBD-23, HBD-27 and HBD-29. Subsequently, these predictions were compared with the known mature peptide sequences of HBD-1, HBD-2, HBD-3 and HBD-4 to predict which amino terminal variants were most likely to yield biologically active $\beta$-defensins (Figure 1). Similarly, the mature carboxy termini of HBD-19, HBD-23, HBD-27 and HBD-29 were predicted by comparison with the known mature $\beta$-defensin peptide sequences. The resulting predicted mature HBD-19, HBD-23, HBD-27 and HBD-29 peptides contain the core 6-cysteine motif preceded by four to ten 
amino-terminal amino acid residues and followed by four to six carboxy terminal residues. The predicted mature amino terminal residue of HBD-19 and HBD-23 is glycine, which is also found at the amino terminus of HBD-1, HBD-2 and HBD-3. The predicted mature amino terminal residue of HBD-27 is glutamic acid like HBD-4 and the predicted mature amino terminal residue of HBD-29 is valine. All four of the predicted mature human $\beta$-defensins terminate with a positively charged amino acid, as do HBD-1 and HBD-3.

Figure 1. Sequences of known and predicted human $\beta$-defensins. The known sequences of HBD-1, 2, 3 and 4 are aligned with the predicted sequences of HBD-19, 23, 27 and 29. The synthetic versions of the latter four human $\beta$-defensins used in this study have the sequences shown. Gaps were introduced to align cysteine residues, which are shaded. Amino and carboxy terminal residues are in bold font.

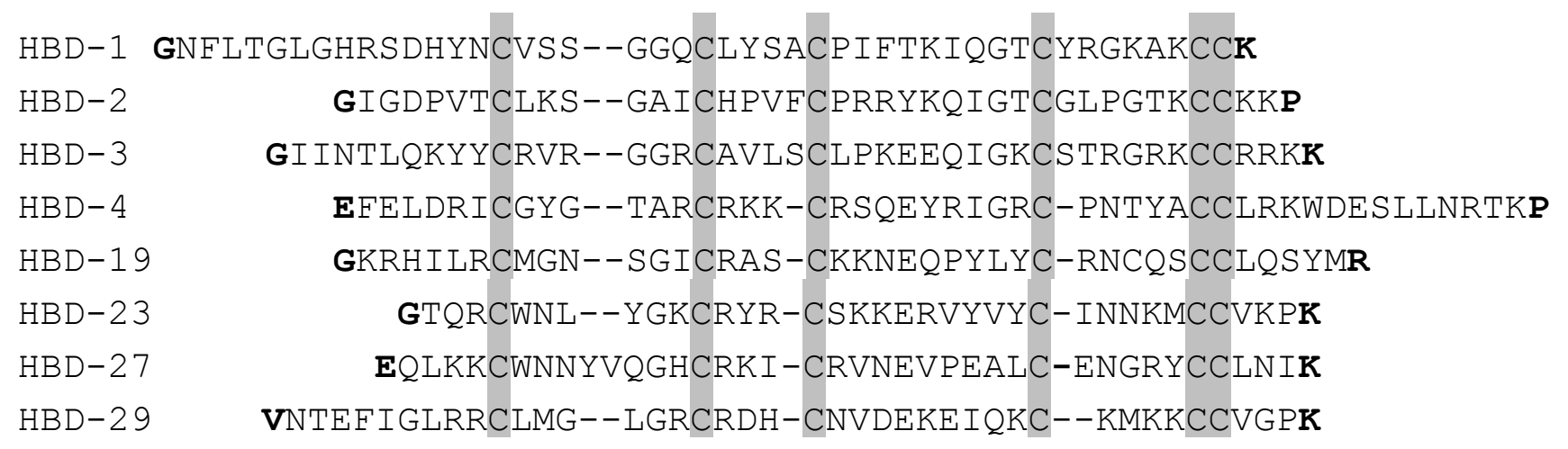

\subsection{Refolding Synthetic Defensins}

After reducing the peptides and allowing them to slowly refold, we analyzed their structural homogeneity by comparing the folded and unfolded forms on C-18 reverse-phase HPLC. We also analyzed the folded forms by SDS-PAGE under non-reducing (NR) and reducing conditions (R) to detect the presence of multimers. More than $95 \%$ of each peptide refolded to a single monomeric foldamer as indicated by the near uniform mobility of each peptide on C-18 reverse-phase HPLC (data not shown) and in SDS-PAGE under reducing and non-reducing conditions (Figure 2).

Figure 2. SDS-PAGE analysis of refolded synthetic human $\beta$-defensins. (A) HBD-19 and (B) HBD-23, HBD-27 and HBD-29 were examined in reduced (R) and non-reduced (NR) states by SDS-PAGE on $15 \%$ polyacrylamide gels followed by staining with Commassie blue dye.

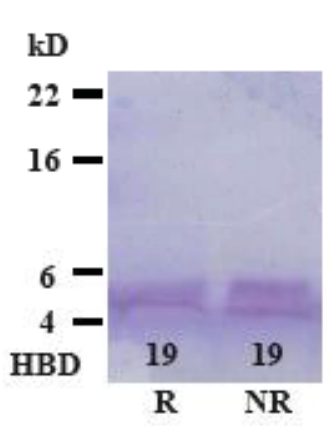

(A)

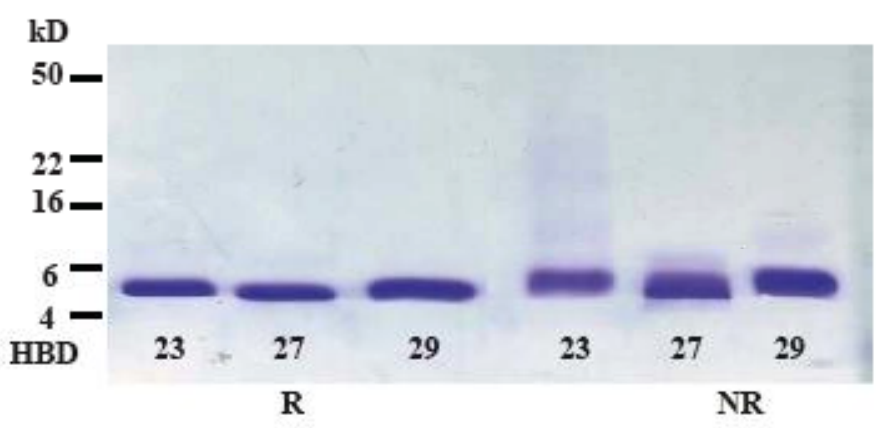

(B) 


\subsection{Antibacterial Activity Assay of Synthetic Defensins}

The antibacterial activity of each peptide, for E. coli, S. aureus and P. aeruginosa was evaluated using the reduction of colony forming unit (CFU) assay. Each peptide was tested at concentrations ranging from 3 to $100 \mu \mathrm{g} / \mathrm{mL}$ in a low ionic strength buffer. Lysozyme was used as a positive control for antibacterial activity. Moreover, each peptide was tested at one concentration in a high ionic strength solution and separately, in the presence of a reducing agent in order to probe the structural requirements of their antibacterial activities.

HBD-19 had antibacterial activity against E. coli ML35, and S. aureus ATCC 25923, but little against $P$. aeruginosa ATCC 27853 (Figure 3). At $100 \mu \mathrm{g} / \mathrm{mL}$ HBD-19 reduced the number of $E$. coli colonies 134-fold, the number of $S$. aureus colonies 20 -fold and the number of $P$. aeruginosa colonies almost 10 -fold. Its activity towards $E$. coli was significantly reduced when $150 \mathrm{mM} \mathrm{NaCl}(\mathrm{p}=0.001)$ or $2 \mathrm{mM}$ DTT $\left(\mathrm{p}=1.4 \times 10^{-8}\right.$ ) was added. Only DTT significantly attenuated the anti-S. aureus activity of HBD-19 $\left(\mathrm{p}=4.5 \times 10^{-5}\right)$. In contrast, neither $150 \mathrm{mM} \mathrm{NaCl}$ nor $2 \mathrm{mM}$ DTT had a significant effect on $E$. coli colony numbers alone. Both agents inhibited $S$. aureus colony formation significantly alone, but the inhibition was less than 2.5 fold in both cases so it did not obscure the attenuation of HBD-19 antibacterial activity against $S$. aureus. Neither $150 \mathrm{mM} \mathrm{NaCl}$ nor $2 \mathrm{mM}$ DTT had a significant effect on $P$. aeruginosa colony numbers alone, $\mathrm{p}=0.11$ and $\mathrm{p}=0.31$ respectively, but paradoxically both agents potentiated HBD-19's activity against $P$. aeruginosa colony formation, albeit modestly, 4.7 and 8.1 fold respectively.

Figure 3. Antimicrobial activity of HBD-19 against three bacterial species. The antimicrobial activity of HBD-19 was evaluated by colony forming unit (CFU) assay and the results were plotted on a logarithmic scale. The experiments were carried out using four different concentrations of HBD-19 $(3 \mu \mathrm{g} / \mathrm{mL}, 10 \mu \mathrm{g} / \mathrm{mL}, 30 \mu \mathrm{g} / \mathrm{mL}, 100 \mu \mathrm{g} / \mathrm{mL})$ with $20 \mathrm{mM}$ lysozyme (square) as the positive bactericidal control. The bactericidal activity of $30 \mu \mathrm{g} / \mathrm{mL}$ HBD-19 was also tested in the presence of $150 \mathrm{mM} \mathrm{NaCl}$ (triangle) and $2 \mathrm{mM}$ dithiothreitol (circle). The bacteria used were Escherichia coli ML35, Staphylococcus aureus ATCC 25923, and Pseudomonas aeruginosa ATCC 27853. The results shown are the average of six complete experiments with E. coli, four with $S$. aureus and five with $P$. aeruginosa; while some points on the graphs represent more experimental repetitions. Error bars show standard deviations.

E. coli ML35

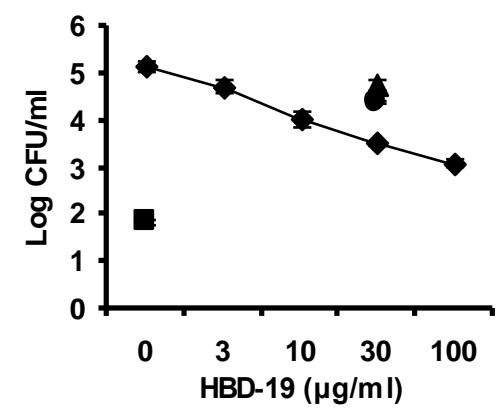

S. aureus ATCC 25923

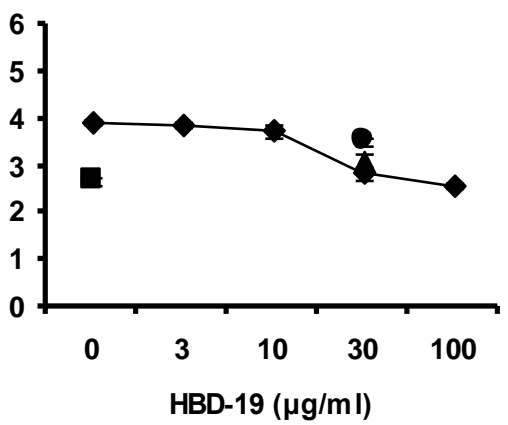

P. aeruginosa ATCC 27853

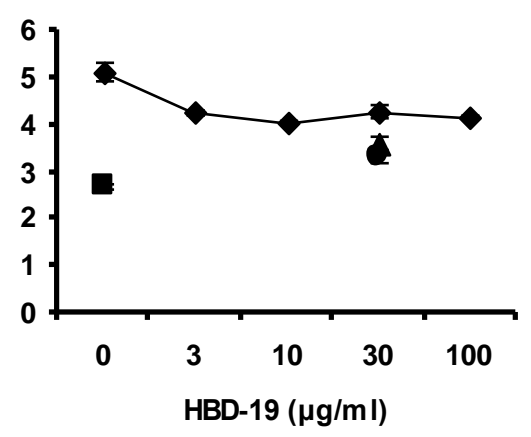


Among the four defensins tested, HBD-23 exerted the strongest antibacterial activity (Figure 4). At $100 \mu \mathrm{g} / \mathrm{mL}, \mathrm{HBD}-23$ reduced the number of E. coli colonies by nearly five logs $\left(5.6 \times 10^{4}\right.$-fold $)$, the number of $S$. aureus colonies 185 -fold and the number of $P$. aeruginosa colonies by more than five $\operatorname{logs}\left(1.4 \times 10^{5}\right.$-fold $)$. The anti- $E$. coli activity of $30 \mu \mathrm{g} / \mathrm{mL}$ HBD-23 was decreased under physiological salt conditions $(\mathrm{p}=0.004)$ and enhanced by $2 \mathrm{mM}$ DTT $\left(\mathrm{p}=7.7 \times 10^{-5}\right)$. As stated above, neither agent affected $E$. coli colony formation alone. The addition of $2 \mathrm{mM}$ DTT did not significantly affect the anti-S. aureus activity of HBD-23 but addition of $150 \mathrm{mM} \mathrm{NaCl}$ attenuated this activity $\left(\mathrm{p}=7.6 \times 10^{-6}\right)$. As above for HBD-19, the modest inhibition of $S$. aureus colony formation mediated by $\mathrm{NaCl}$ alone did not mask its ten-fold attenuation of the anti-S. aureus activity of HBD-23. Both $\mathrm{NaCl}$ and DTT significantly inhibited the anti- $P$. aeruginosa activity of HBD-23 ( $p=0.007$ and 0.001 respectively), but as stated above neither agent significantly affected $P$. aeruginosa colony formation alone.

Figure 4. Antimicrobial activity of HBD-23 against three bacterial species. The antimicrobial activity of HBD-23 was evaluated by colony forming unit (CFU) assay and plotted on a logarithmic scale. The experiments were carried out using four different concentrations of HBD-23 (3 $\mu \mathrm{g} / \mathrm{mL}, 10 \mu \mathrm{g} / \mathrm{mL}, 30 \mu \mathrm{g} / \mathrm{mL}, 100 \mu \mathrm{g} / \mathrm{mL})$ with $20 \mathrm{mM}$ lysozyme (square) as the positive bactericidal control. The bactericidal activity of $30 \mu \mathrm{g} / \mathrm{mL}$ HBD-23 was also tested in the presence of $150 \mathrm{mM} \mathrm{NaCl}$ (triangle) and $2 \mathrm{mM}$ dithiothreitol (circle). The bacteria used were Escherichia coli ML35, Staphylococcus aureus ATCC 25923, and Pseudomonas aeruginosa ATCC 27853. The results shown are the average of three complete experiments with $E$. coli, five with $S$. aureus and five with $P$. aeruginosa; while some points on the graphs represent more experimental repetitions. Error bars show standard deviations.

E. coli ML35

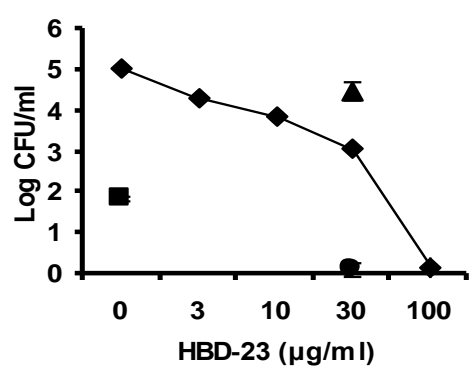

S. aureus ATCC 25923

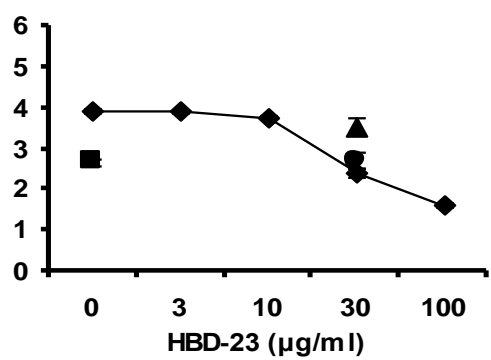

P. aeruginosa ATCC 27853

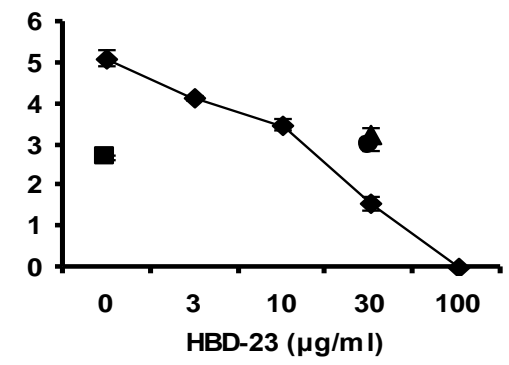

Unlike HBD-23, HBD-27 showed little antibacterial activity against E. coli or P. aeruginosa (Figure 5). HBD-27 was weakly active, however, against $S$. aureus, but only at high concentrations. At $100 \mu \mathrm{g} / \mathrm{mL}$ HBD-27 reduced the number of $P$. aeruginosa colonies by nearly 22 -fold. This modest antibacterial activity of HBD-27 against $P$. aeruginosa was attenuated by the addition of $150 \mathrm{mM}$ $\mathrm{NaCl}(\mathrm{p}=0.001)$ or by the addition of $2 \mathrm{mM}$ DTT $(\mathrm{p}=0.02)$. 
Figure 5. Antimicrobial activity of HBD-27 against three bacterial species. The antimicrobial activity of HBD-27 was evaluated by colony forming unit (CFU) assay and plotted on a logarithmic scale. The experiments were carried out using four different

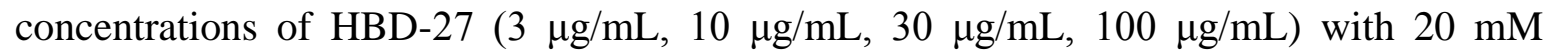
lysozyme (square) as the positive bactericidal control. The bactericidal activity of $30 \mu \mathrm{g} / \mathrm{mL}$ HBD-27 was also tested in the presence of $150 \mathrm{mM} \mathrm{NaCl}$ (triangle) and $2 \mathrm{mM}$ dithiothreitol (circle). The bacteria used were Escherichia coli ML35, Staphylococcus aureus ATCC 25923, and Pseudomonas aeruginosa ATCC 27853. The results shown are the average of six complete experiments with $E$. coli, six with $S$. aureus and five with $P$. aeruginosa; while some points on the graphs represent more experimental repetitions. Error bars show standard deviations.

E. coli ML35

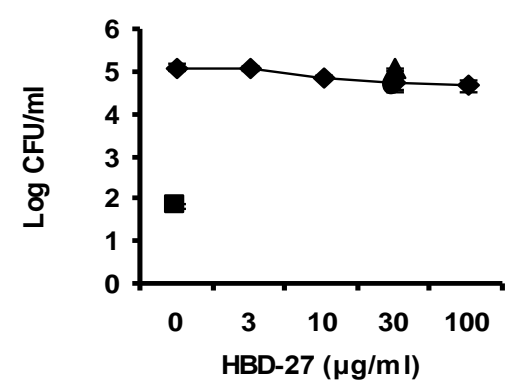

S. aureus ATCC 25923

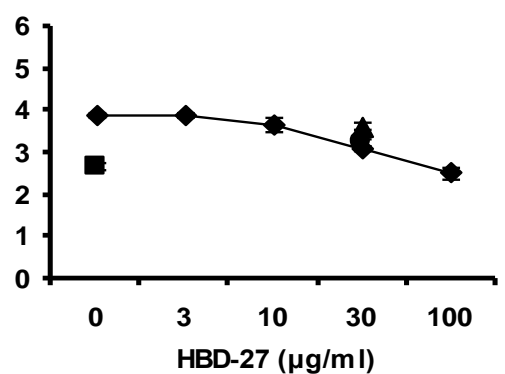

P. aeruginosa ATCC 27853

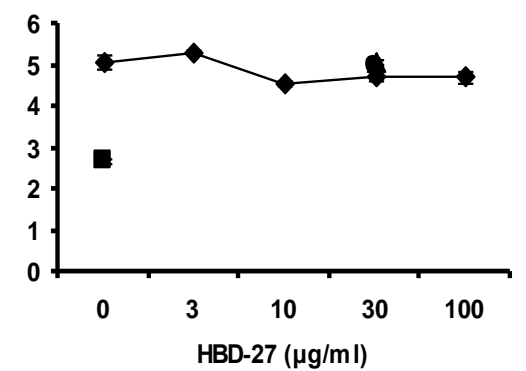

Figure 6. Antimicrobial activity of HBD-29 against three bacterial species. The antimicrobial activity of HBD-29 was evaluated by colony forming unit (CFU) assay and plotted on a logarithmic scale. The experiments were carried out using four different concentrations of HBD-29 (3 $\mu \mathrm{g} / \mathrm{mL}, 10 \mu \mathrm{g} / \mathrm{mL}, 30 \mu \mathrm{g} / \mathrm{mL}, 100 \mu \mathrm{g} / \mathrm{mL})$ with $20 \mathrm{mM}$ lysozyme (square) as the positive bactericidal control. The bactericidal activity of $30 \mu \mathrm{g} / \mathrm{mL}$ HBD-29 was also tested in the presence of $150 \mathrm{mM} \mathrm{NaCl}$ (triangle) and $2 \mathrm{mM}$ dithiothreitol (circle). The bacteria used were Escherichia coli ML35, Staphylococcus aureus ATCC 25923, and Pseudomonas aeruginosa ATCC 27853. The results shown are the average of five complete experiments with $E$. coli, four with $S$. aureus and five with $P$. aeruginosa; while some points on the graphs represent more experimental repetitions. Error bars show standard deviations.

E. coli ML35

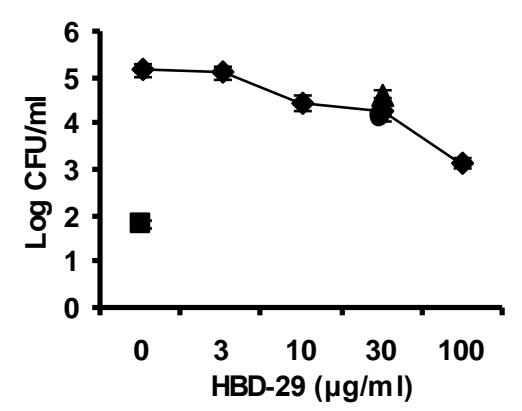

S. aureus ATCC 25923

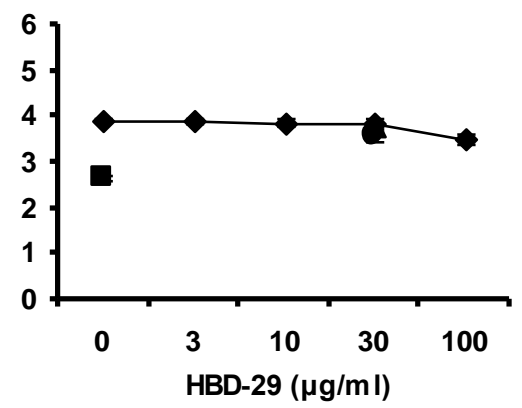

P. aeruginosa ATCC 27853

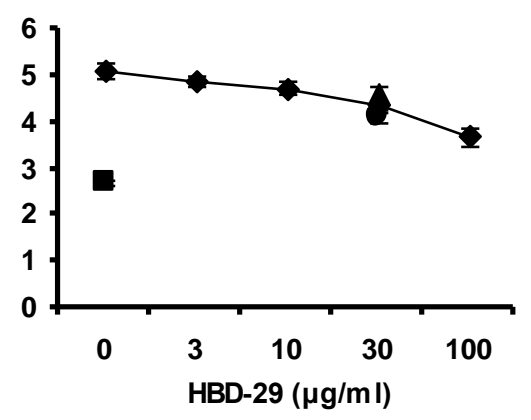


Lastly, HBD-29 exhibited antibacterial activity against E. coli and P. aeruginosa, but had little to no activity against $S$. aureus (Figure 6). At $100 \mu \mathrm{g} / \mathrm{mL}$ HBD-29 reduced the number of $E$. coli colonies 112-fold and the number of $P$. aeruginosa colonies 26-fold. The antibacterial activity of HBD-29 against $E$. coli was attenuated by $\mathrm{NaCl}(\mathrm{p}=0.0006)$, but not by DTT. In contrast, its activity against $P$. aeruginosa was blocked by DTT $(\mathrm{p}=0.002)$, but not by $\mathrm{NaCl}$.

\subsection{Cellular Toxicity in Peripheral Blood Mononuclear Cells}

Previous studies reported that defensins interact electrostatically with bacterial membranes and thereby destroy their structure $[3,12,14]$. Thus, it is important to know whether these peptides can similarly interfere with human cellular membranes. The cellular toxicity of HBD-19, HBD-23, HBD-27, and HBD-29, both in their crude and folded states, was investigated using a colorimetric metabolic-activity assay on human peripheral blood mononuclear cells (PBMC; Figure 7).

Figure 7. HBD cytotoxicity on human peripheral blood mononuclear cells (PBMCs). The cellular toxicity of folded (F) and crude (C) HBD-19, HBD-23, HBD-27, and HBD-29 was analyzed by measuring the amount of the tetrazolium salt MTS reduced to a colored product by PBMCs after 3 days of incubation with various concentrations of defensins. The results shown are the average of three experiments and the error bars represent the standard deviations.
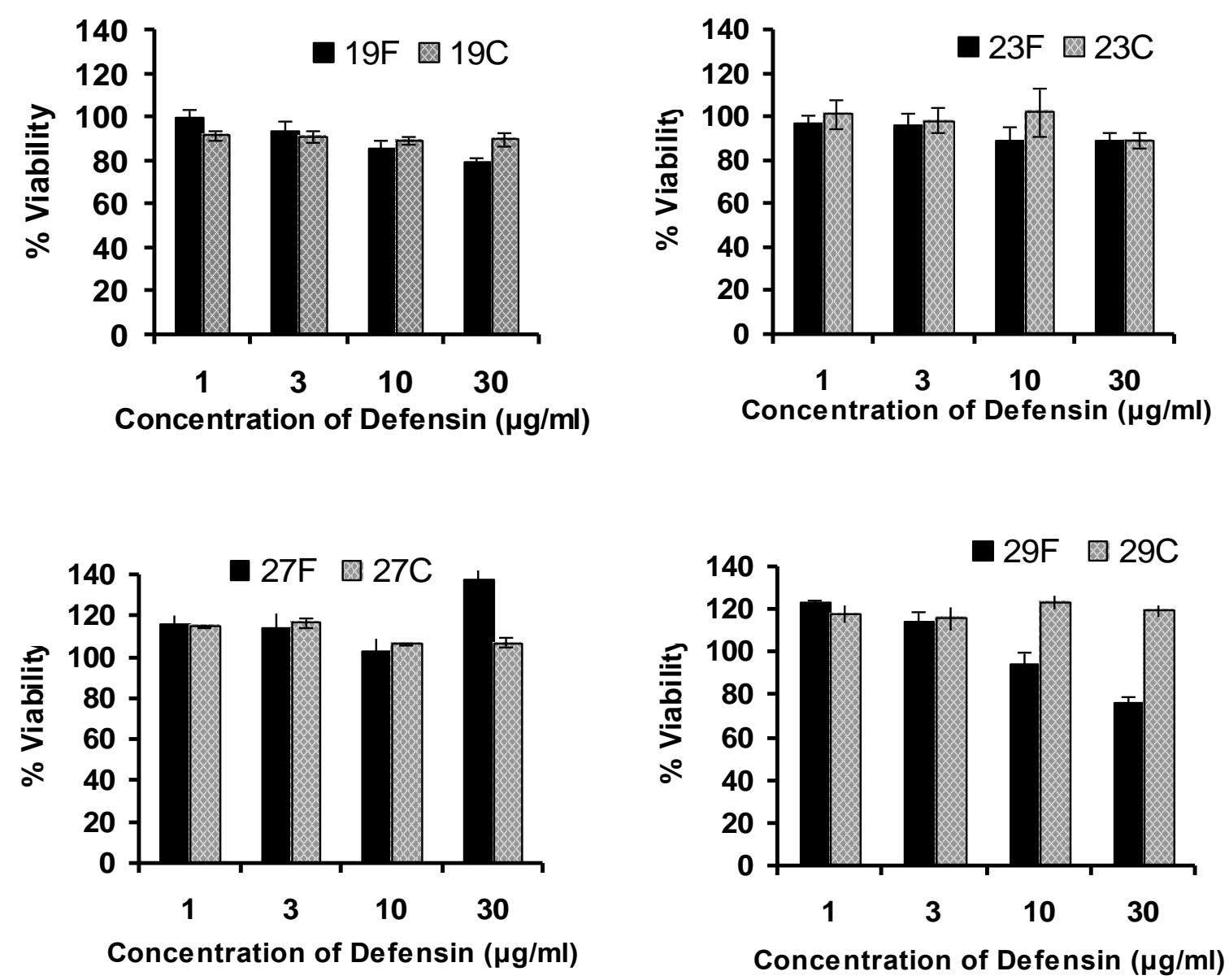
Folded HBD-19 showed a low level of cellular toxicity that was concentration dependent, reaching $20 \%$ at $30 \mu \mathrm{g} / \mathrm{mL}$. Crude HBD-19, however, had little effect on PBMC viability. Likewise, crude and folded HBD-23 and HBD-27 demonstrated little or no cytotoxicity. In fact, folded HBD-27 was somewhat stimulatory, particularly at $30 \mu \mathrm{g} / \mathrm{mL}$. In contrast, folded HBD-29 exhibited concentration dependent toxicity for PBMC; up to $23 \%$ at $30 \mu \mathrm{g} / \mathrm{mL}$, while crude HBD-29 stimulated PBMC metabolism slightly.

\subsection{Discussion}

This study examined the antibacterial properties of four human $\beta$-defensins-HBD-19, 23, 27, and 29-that are normally expressed, at least at the RNA level, in the male reproductive tract [19-21]. Because the epididymis is anatomically continuous with the urethra, host defense against ascending bacterial pathogens is pertinent in the protection of spermatozoa from bacterial contamination. Previous studies showed HBD-1 and HBD-4 are also expressed in the urinary tract and are known to be microbicidal [7,24].

The results of this study showed HBD-23 to be the most potent antibacterial agent among the four defensins tested. However, we found the antibacterial activity of HBD-23 was reduced in the presence of salt, an effect that has been documented by Shimoda et al, who observed that ultrastructural changes on the S. aureus surface caused by defensins were prevented at high-salt concentration [14]. This supports the hypothesis that HBD-23, like other previously studied antimicrobial defensins, permeabilizes the bacterial cell membrane by an electrostatic charge-based mechanism $[12,25,26]$. Antimicrobial peptides can also damage eukaryotic cells in the same manner [3]. Our data revealed that refolded HBD-19 and HBD-29 decreased cellular viability in a dose-dependent manner. However, HBD-23, and HBD-27 demonstrated low levels of cytotoxicity on human peripheral blood mononuclear cells, which is in agreement with some other defensins demonstrating low levels of hemolytic activities [16]. The presence of cholesterol and lipid-anchored proteins may interfere with defensin binding, preventing host damage [27,28].

We found that HBD-23 killed E. coli more efficiently in vitro when its disulfide bridges were reduced. This may be due to the positive charges being more exposed to anionic bacterial membrane and thereby killing at a faster rate. Nevertheless, it remains to be determined whether these disulfide bridges have a functional role in vivo, as one study reported that they stabilize defensins against enzymatic digestion [29].

Interestingly, Hwang et al showed that certain defensins are more efficient in killing bacteria when more positive charges are present within the cysteine core region [30]. This may explain why HBD-23 was the most potent as it contained the most net positive charges within the six cysteine motif, followed by HBD-29, HBD-19, and finally HBD-27, which showed the least amount of killing. These observations were consistent with the data presented by Rodríguez-Jiménez, who found that synthetic HBD-23 and HBD-29 had broad spectrums of antibacterial activity, while HBD-27 did not [20].

The human $\beta$-defensins studied here may also have other roles in immune defense including antiviral activity like HBD-2 and HBD-3 [4,31,32]. Moreover, multiple studies have reported that $\beta$-defensins recruit monocytes, T-cells, immature dendritic cells and activated neutrophils by acting as chemokines that interact with the chemokine receptors CCR2 and CCR6 [15-18,33]. Human 
$\beta$-defensins 1-4 activate keratinocytes to produce IL-18 and HBD-3 also activates macrophages and myeloid dendritic cells via the toll-like receptors (TLR) 1 and 2 [34,35]. Further investigation of HBD-19, 23, 27 and 29 may therefore shed more light on the intricate functions of human immunity.

\section{Conclusions}

We assayed the antibacterial properties of synthetic HBD-19, HBD-23, HBD-27, and HBD-29 against three species of clinically relevant bacteria: Escherichia coli, Staphylococcus aureus and Pseudomonas aeruginosa. HBD-23 was by far the most potent peptide against all three species of bacteria. Moreover, HBD-23 exhibited very modest toxicity for normal human peripheral blood mononuclear cells at concentrations that inhibited the growth of the Gram-negative species E. coli and $P$. aeruginosa by five logs and the Gram-positive bacterium, S. aureus by more than two logs.

\section{Acknowledgments}

Maira Soto was the recipient of a California HIV/AIDS Research Program Research Training Award, and both Bryan Chow and Bonnie Lo received support from the University of California, Irvine Undergraduate Research Opportunity Program, for which we thank the funding agencies. We would also like to thank Hugh Fisher for helpful discussions and Kimberly Lam for excellent technical support.

\section{References}

1. Ganz, T.; Selsted, M.E.; Szklarek, D.; Harwig, S.S.; Daher, K.; Bainton, D.F.; Lehrer, R.I. Defensins. Natural peptide antibiotics of human neutrophils. J. Clin. Invest. 1985, 76, 1427-1435.

2. Lehrer, R.I.; Daher, K.; Ganz, T.; Selsted, M.E. Direct inactivation of viruses by MCP-1 and MCP-2, natural peptide antibiotics from rabbit leukocytes. J. Virol. 1985, 54, 467-472.

3. Lehrer, R.I.; Lichtenstein, A.K.; Ganz, T. Defensins: Antimicrobial and cytotoxic peptides of mammalian cells. Annu. Rev. Immunol. 1993, 11, 105-128.

4. Seidel, A.; Ye, Y.; de Armas, L.R.; Soto, M.; Yarosh, W.; Marcissin, R.; Tran, P.; Selsted, M.; Camerini, D. Cyclic and acyclic defensins inhibit human immunodeficiency virus type-1 replication by different mechanisms. PLoS One 2010, 5, doi:10.1371/journal.pone.0009737.

5. Selsted, M.E.; Szklarek, D.; Oppenheim, J.J.; Hehlgans, T. Purification and antibacterial activity of antimicrobial peptides of rabbit granulocytes. Infect. Immun. 1984, 45, 150-154.

6. García, J.R.; Jaumann, F.; Schulz, S.; Krause, A.; Rodríguez-Jiménez, F.J.; Forssmann, U.; Adermann, K.; Klüver, E.; Vogelmeier, C.; Becker, D.; et al. Identification of a novel, multifunctional beta-defensin (human beta-defensin 3) with specific antimicrobial activity. Its interaction with plasma membranes of Xenopus oocytes and the induction of macrophage chemoattraction. Cell Tissue Res. 2001, 306, 257-264.

7. García, J.R.; Krause, A.; Schulz, S.; Rodríguez-Jiménez, F.J.; Klüver, E.; Adermann, K.; Forssmann, U.; Frimpong-Boateng, A.; Bals, R.; Forssmann, W.G. Human beta-defensin 4: A novel inducible peptide with a specific salt-sensitive spectrum of antimicrobial activity. FASEB J. 2001, 15, 1819-1821. 
8. Maisetta, G.; Batoni, G.; Esin, S.; Luperini, F.; Pardini, M.; Bottai, D.; Florio, W.; Giuca, M.R.; Gabriele, M.; Campa, M. Activity of human beta-defensin 3 alone or combined with other antimicrobial agents against oral bacteria. Antimicrob. Agents Chemother. 2003, 47, 3349-3351.

9. Tomita, T.; Hitomi, S.; Nagase, T.; Matsui, H.; Matsuse, T.; Kimura, S.; Ouchi, Y. Effect of ions on antibacterial activity of human beta defensin 2. Microbiol. Immunol. 2000, 44, 749-754.

10. Valore, E.V.; Park, C.H.; Quayle, A.J.; Wiles, K.R.; McCray, P.B., Jr.; Ganz, T. Human beta-defensin 1: An antimicrobial peptide of urogenital tissues. J. Clin. Invest. 1998, 101, 1633-1642.

11. Hancock, R.E.; Lehrer, R. Cationic peptides: A new source of antibiotics. Trends. Biotechnol. 1998. $16,82-88$.

12. Kagan, B.L.; Selsted, M.E.; Ganz, T.; Lehrer, R.I. Antimicrobial defensin peptides form voltage-dependent ion permeable channels in planar lipid bilayer membranes. Proc. Natl. Acad. Sci. USA 1990, 87, 210-214.

13. Harder, J.; Bartels, J.; Christophers, E.; Schroder, J.M. Isolation and characterization of human beta-defensin-3, a novel human inducible peptide antibiotic. J. Biol. Chem. 2001, 276, 5707-5713.

14. Shimoda, M.; Ohki, K.; Shimamoto, Y.; Kohashi, O. Morphology of defensin-treated Staphylococcus aureus. Infect. Immun. 1995, 63, 2886-2891.

15. Chertov, O.; Michiel, D.F.; Xu, L.; Wang, J.M.; Tani, K.; Murphy, W.J.; Longo, D.L.; Taub, D.D.; Oppenheim, J.J. Identification of defensin-1, defensin-2, and CAP37/azurocidin as T-cell chemoattractant proteins released from interleukin-8-stimulated neutrophils. J. Biol. Chem. 1996, 271, 2935-2940.

16. Niyonsaba, F.; Ogawa, H.; Nagaoka, I Human beta-defensin-2 functions as a chemotactic agent for tumour necrosis factor-alpha-treated human neutrophils. Immunology 2004, 111, 273-281.

17. Rorhl, J.; Yang, D.; Lehrer, R.I. Human beta-defensin 2 and 3 and their mouse orthologs induce chemotaxis through interaction with CCR2. J. Immunol. 2010, 184, 6688-6694.

18. Yang, D.; Chertov, O.; Bykovskaia, S.N.; Chen, Q.; Buffo, M.J.; Shogan, J.; Anderson, M.; Schröder, J.M.; Wang, J.M.; Howard, O.M.; et al. Beta-defensins: Linking innate and adaptive immunity through dendritic and T cell CCR6. Science 1999, 286, 525-528.

19. Radhakrishnan, Y.; Hamil, K.G.; Yenugu, S.; Young, S.L.; French, F.S.; Hall, S.H. Identification, characterization, and evolution of a primate beta-defensin gene cluster. Genes Immun. 2005, 6, 203-210.

20. Rodríguez-Jiménez, F.J. Identification and characterization of three new human beta-defensins: hBD23, hBD27, hBD29. Ph.D. dissertation, University of Hanover, Hannover, Germany, 2003.

21. Rodríguez-Jiménez, F.J.; Krause, A.; Schulz, S.; Forssmann, W.G.; Conejo-Garcia, J.R.; Schreeb, R.; Motzkus, D. Distribution of new human beta-defensin genes clustered on chromosome 20 in functionally different segments of epididymis. Genomics 2003, 81, 175-183.

22. SignalP 4.0 Server. Available online at: http://www.cbs.dtu.dk/services/SignalP (accessed on 1 February 2012).

23. Llenado, R.A.; Weeks, C.S.; Cocco, M.J.; Ouellette, A. Electropositive charge in alpha-defensin bactericidal activity: Functional effects of Lys-for-Arg substitutions vary with peptide primary structure. Infect. Immun. 2009, 77, 5035-5043. 
24. Com, E.; Bourgeon, F.; Evrard, B.; Ganz, T.; Colleu, D.; Jégou, B.; Pineau, C. Expression of antimicrobial defensins in the male reproductive tract of rats, mice, and humans. Biol. Reprod. 2003, 68, 95-104.

25. Hoover, D.M.; Rajashankar, K.R.; Blumenthal, R.; Puri, A.; Oppenheim, J.J.; Chertov, O.; Lubkowski, J. The structure of the human beta-defensin-2 shows evidence of higher order oligomerization. J. Biol. Chem. 2000, 275, 32911-32918.

26. Zou, G.; de Leeuw, E.; Li, C.; Pazgier, M.; Li, C.; Zeng, P.; Lu, W.Y.; Lubkowski, J.; Lu, W. Toward understanding the cationicitiy of defensins. Arg and Lys versus their noncoded analogs. J. Biol. Chem. 2007, 27, 19653-19665.

27. Boman, H.G. Innate immunity and the normal microflora. Immunol. Rev. 2000, 173, 5-16.

28. Matsuzaki, K.; Horikiri, C. Interactions of amyloid beta-peptide (1-40) with ganglioside-containing membranes. Biochemistry 1999, 38, 4137-4142.

29. Tanabe, H.; Ayabe, T.; Maemoto, A.; Ishikawa, C.; Inaba, Y.; Sato, R.; Moriichi, K.; Okamoto, K.; Watari, J.; Kono, T.; et al. Denatured human alpha-defensin attenuates the bactericidal activity and the stability against enzymatic digestion. Biochem Biophys Res Commun. 2007, 358, 349-355.

30. Hwang, P.M.; Vogel, H.J. Structure-function relationships of antimicrobial peptides. Biochem. Cell. Biol. 1998, 76, 235-246.

31. Quinones-Mateu, M.E.; Lederman, M.M.; Feng, Z.; Chakraborty, B.; Weber, J.; Rangel, H.R.; Marotta, M.L.; Mirza, M.; Jiang, B.; Kiser, P.; et al. Human epithelial beta-defensins 2 and 3 inhibit HIV-1 replication. AIDS 2003, 17, F39-F48.

32. Sun, L.; Finnegan, C.M.; Kish-Catalone, T.; Blumenthal, R.; Garzino-Demo, P.; La Terra Maggiore, G.M.; Berrone, S.; Kleinman, C.; Wu, Z.; Abdelwahab, S.; et al. Human beta-defensins suppress human immunodeficiency virus infection: Potential role in mucosal protection. J. Virol. 2005, 79, 14318-14329.

33. Territo, M.C.; Ganz, T.; Selsted, M.E.; Lehrer, R. Monocyte-chemotactic activity of defensins from human neutrophils. J. Clin. Invest. 1989, 84, 2017-2020.

34. Funderburg, N.; Lederman, M.M.; Feng, Z.; Drage, M.G.; Jadlowsky, J.; Harding, C.V.; Weinberg, A.; Sieg, S.F. Human beta-defensin-3 activates professional antigen-presenting cells via Toll-like receptors 1 and 2. Proc. Natl. Acad. Sci. USA 2007, 104, 18631-18635.

35. Niyonsaba, F.; Ushio, H.; Nagaoka, I.; Okumura, K.; Ogawa, H. The human beta-defensins $(-1,-2,-3,-4)$ and cathelicidin LL-37 induce IL-18 secretion through p38 and ERK MAPK activation in primary human keratinocytes. J. Immunol. 2005, 175, 1776-1784.

(C) 2012 by the authors; licensee MDPI, Basel, Switzerland. This article is an open access article distributed under the terms and conditions of the Creative Commons Attribution license (http://creativecommons.org/licenses/by/3.0/). 